\title{
UNIFORMIZAÇÃO, COLETIVIZAÇÃO E ESTRUTURAÇÃO PROCESSUAL DA TUTELA DA SAÚDE SOB O ENFOQUE DA ANÁLISE ECONÔMICA DO DIREITO
}

\author{
UNIFORMIZATION, COLLECTIVIZATION AND PROCESSUAL \\ STRUCTURING OF HEALTH CARE UNDER THE APPROACH OF \\ ECONOMIC ANALYSIS OF LAW
}

Recebimento: 10 set. 2019

Aceitação: 1 mar. 2021

\begin{abstract}
Elton Venturi
Doutor em Direito

Afiliação institucional: Universidade Federal do Paraná - UFPR - (Curitiba, PR, Brasil) Lattes iD: http://lattes.cnpq.br/2638684214525545

Email: eventuri@uol.com.br

Thaís Goveia Pascoaloto Venturi

Doutora em Direito

Afiliação institucional: Universidade Tuiuti do Paraná - UTP - (Curitiba, PR, Brasil)

Lattes iD: http://lattes.cnpq.br/4696974170339835

Email: thaisgpv@uol.com.br
\end{abstract}

Como citar este artigo / How to cite this article (informe a data atual de acesso / inform the current date of access):

VENTURI, Elton; VENTURI, Thaís Goveia Pascoaloto. Uniformização, coletivização e estruturação processual da tutela da saúde sob o enfoque da análise econômica do direito. Revista da Faculdade de Direito UFPR, Curitiba, v. 65, n. 3, p. 115-138, set./dez. 2020. ISSN 2236-7284. Disponível em: https://revistas.ufpr.br/direito/article/view/69142. Acesso em: 31 dez. 2020. DOI: http://dx.doi.org/10.5380/rfdufpr.v65i3.69142.

\section{RESUMO}

O objetivo geral deste artigo é demonstrar que os processos adjudicatórios de conflitos relativos à prestação de políticas públicas de saúde devem ser norteados pela racionalização e equidade da proteção dos direitos fundamentais. Para fundamentar essa posição, parte-se metodologicamente da análise de precedentes vinculantes dos tribunais superiores a respeito dos critérios a serem observados por ocasião de julgamentos envolvendo pretensões de tutela da saúde. Sustenta-se que o sistema de justiça não pode prescindir da utilização de técnicas de uniformização, coletivização e estruturação procedimental, sem as quais o modelo de admissão de demandas individuais - que impulsiona fortemente o fenômeno da "judicialização da saúde" - resulta numa espécie de apropriação privada da política pública. Valendo-se de revisão bibliográfica pautada na escola da análise econômica do Direito, objetiva-se especificamente indagar até que ponto seria desejável ou viável a adoção de racionalidades econômicas no campo da tutela jurisdicional dos direitos fundamentais, bem como se isso poderia de fato implicar uma maior eficiência a um menor custo para o sistema de saúde. Em seguida, expõe-se como resultado que, paradoxalmente, a tolerância ou o incentivo ao ajuizamento de ações individuais em matéria de saúde pública contraria princípios constitucionais que lhe são inerentes, relativos à universalidade, isonomia e preventividade. Por fim, a partir de pesquisa aplicada, propõe-se que as ações individuais pelas quais se persegue a implementação de políticas 
públicas sejam coletivizadas, no intuito de possível irradiação de eficácia erga omnes da tutela jurisdicional, em benefício de todos.

\title{
PALAVRAS-CHAVE
}

Saúde pública. Acesso à justiça. Ações coletivas. Processo estrutural. Análise econômica do Direito.

\begin{abstract}
The general objective of this article is to demonstrate that the adjudication processes of conflicts related to the provision of public health policies must be guided by the rationalization and equity of the protection of fundamental rights. In order to substantiate this position, the methodology starts from the analysis of binding precedents of the Brazilian superior courts regarding the criteria to be observed when judgments involving health protection claims are made. It is argued that the justice system cannot leave aside the use of standardization, collectivization and procedural structuring techniques, without which the model for admitting individual demands - which strongly drives the phenomenon of "judicialization of health" - results in a kind of private appropriation of public policy. By means of bibliographic research, based on a critical verification of the economic analysis of law, this article has the specific objective to inquire to what extent it would be desirable or viable to adopt economic rationalities in the field of jurisdictional protection of fundamental rights, as well as whether this possibility could in fact imply greater efficiency at a lower cost for the health system. Then, as a result, it is exposed that, paradoxically, tolerance or incentive to file individual actions in public health matters is contrary to constitutional principles inherent to it, related to universality, isonomy and preventivity. Finally, based on applied research, it is proposed that individual actions by which public policies are pursued should be collectivized, in order to radiate the erga omnes effectiveness of jurisdictional protection for the benefit of all.
\end{abstract}

\section{KEYWORDS}

Public health. Access to justice. Collective actions. Structural process. Economic analysis of law.

\section{O CONTROLE JUDICIAL DAS POLÍTICAS PÚBLICAS: DA RESERVA DO IMPOSSÍVEL AO ESTADO DE COISAS SURREAL}

O tema relativo à judicialização das políticas públicas, apesar de não ser recente, tornou-se extremamente caro ao sistema de justiça brasileiro na medida em que passaram a crescer exponencialmente, pelo País afora, demandas judiciais pelas quais são pleiteadas as mais diversas prestações por parte do Poder Público a fim de garantir o bem-estar social.

Objetiva-se, em geral, a afirmação dos direitos e das garantias fundamentais inscritos na Constituição Federal de 1988, sonegados ou insatisfatoriamente prestados pela Administração Pública no campo da saúde, da segurança pública, da educação e de outros direitos sociais essenciais ${ }^{1}$.

\footnotetext{
Segundo pesquisa do Instituto Datafolha divulgada em 17/4/2018, a corrupção ocupa o primeiro lugar na lista das maiores preocupações dos brasileiros, sendo apontada por $21 \%$ das pessoas entrevistadas. Em seguida, aparecem a saúde (19\%) e o desemprego e a violência (13\%) (INSTITUTO DATAFOLHA, 2018).
} 
Todavia, como buscar-se-á demonstrar, os processos adjudicatórios de conflitos relativos à prestação de políticas públicas - entre as quais a da saúde - devem ser norteados pela racionalização e equidade da proteção dos direitos fundamentais.

Para fundamentar essa posição, parte-se metodologicamente da análise de precedentes vinculantes dos tribunais superiores a respeito dos critérios a serem observados por ocasião de julgamentos envolvendo pretensões de tutela da saúde, restando claro que o sistema de justiça nacional não pode prescindir da utilização de técnicas de uniformização, coletivização e estruturação procedimental, sem as quais o modelo de admissão de demandas individuais - que impulsiona fortemente o fenômeno da “judicialização da saúde" - resulta numa espécie de apropriação privada da política pública.

Valendo-se de revisão bibliográfica pautada na escola da análise econômica do Direito, objetiva-se especificamente indagar até que ponto seria desejável ou viável a adoção de racionalidades econômicas no campo da tutela jurisdicional dos direitos fundamentais, bem como se isso poderia de fato implicar uma maior eficiência a um menor custo para o sistema de saúde

Com efeito, especificamente no campo da saúde pública, nada obstante os argumentos utilizados em defesa da chamada reserva do possível - envolvendo uma pesquisa estratégica e crítica acerca da análise econômica a respeito da contraposição entre orçamento público, despesas com a manutenção do Sistema Único de Saúde (SUS) e despesas específicas ocasionadas pela concessão de tutelas jurisdicionais ${ }^{2}$-, o Poder Judiciário brasileiro tem se revelado bastante sensível e categórico na priorização da salvaguarda da vida e da saúde, enquanto direitos fundamentais integrantes do mínimo existencial. Nessa linha, o já famoso precedente do Supremo Tribunal Federal (STF) na Arguição de Descumprimento de Preceito Fundamental (ADPF) n. ${ }^{\circ} 45$ assenta:

\begin{abstract}
Argüição de Descumprimento de Preceito Fundamental. A questão da legitimidade constitucional do controle e da intervenção do Poder Judiciário em tema de implementação de políticas públicas, quando configurada hipótese de abusividade governamental. Dimensão política da jurisdição constitucional atribuída ao Supremo Tribunal Federal. Inoponibilidade do arbítrio estatal à efetivação dos direitos sociais, econômicos e culturais. Caráter relativo da liberdade de conformação do legislador. Considerações em torno da cláusula da "reserva do possível”. Necessidade de preservação, em favor dos indivíduos, da integridade e da intangibilidade do núcleo consubstanciador do "mínimo existencial". Viabilidade instrumental da argüição de descumprimento no processo de concretização das liberdades positivas (direitos constitucionais de segunda geração) (BRASIL, 2004).
\end{abstract}

2 A respeito dos inúmeros entraves administrativos à realização das políticas públicas de saúde, ver BUCCI (2017). 
A orientação do sistema jurisdicional nacional, neste particular, não faz mais do que afirmar o pretensioso projeto de Estado Social Democrático de Direito sonhado pelos legisladores da Constituição Cidadã que se foi presenteada em 1988.

Sob a perspectiva da teoria dos direitos e garantias fundamentais, aliás, são conhecidas e frequentes as críticas opostas contra a oficial defesa do Estado, por muitos visto como o inimigo que teima em descumprir a missão que lhe foi constitucionalmente atribuída de custear e garantir a vida e a saúde de seus cidadãos, não importa a qual preço.

Todavia, os rumos da judicialização dos conflitos envolvendo o controle e a implementação das políticas públicas no Brasil apontam para a consagração do princípio da reserva do impossível.

A partir de pesquisa aplicada, percebe-se uma indiscriminada e bilionária concessão judicial de prestações que afetam o Sistema Único de Saúde, no âmbito de milhares de demandas individuais que não pretendem já agora tão somente arguir a inexecução das políticas públicas previamente projetadas pelo SUS. A título exemplificativo, entre os anos de 2010 e 2016, só a União Federal destinou R \$ 4,5 bilhões para atender a determinações judiciais de compra de medicamentos, dietas, suplementos alimentares, além de depósitos judiciais. Estima-se que até o final do ano de 2017 os gastos dos estados, municípios e da União Federal tenham atingido a cifra de R 7 bilhões, conforme notícia extraída do Conselho Nacional de Justiça (JUDICIALIZAÇÃO..., 2018).

Reflexo dessa realidade, de acordo com os apontamentos de Mariana Muniz (2017), pendiam no sistema de justiça brasileiro aproximadamente 1,5 milhão de processos ligados a temas relacionados à saúde, no ano de 2017. Somente entre os anos de 2008 a 2015, os gastos da União e dos estados cresceram $1.300 \%$ devido às demandas judiciais por fornecimento de medicamentos. Segundo o relatório Justiça em Números, do CNJ, no ano de 2019 tramitavam mais de dois milhões de processos versando sobre diversas matérias de saúde ${ }^{3}$.

A percepção de que muitos magistrados, por ativismo ou por constrangimento, simplesmente esquivam-se de qualquer preocupação quanto à verificação de repercussões sistêmicas ou macroeconômicas de suas decisões - sobretudo em relação à evidente quebra da isonomia entre os utentes das mesmas políticas públicas - representa sedução irrefreável para o ajuizamento de ações objetivando que seja imposto à União, estados e municípios (solidários responsáveis pela gestão da saúde pública ${ }^{4}$ ) arcarem com medicamentos e procedimentos de alto custo.

3 Disponível em: https://bit.ly/3tzk52o. Acesso em: 22 jan. 2021.

4 A jurisprudência do Superior Tribunal de Justiça (STJ) fixou-se no sentido da existência de solidariedade passiva entre os entes federativos no que tange a prestações relativas à saúde pública. Precedentes: AgRg no REsp 1028835/DF, Rel. Ministro Luiz Fux, $1^{\text {a }}$ Turma, julgado em 02/12/2008, DJe 15/12/2008; AgRg no Ag 1107605/SC, Rel. Ministro Herman Benjamin, 2a Turma, julgado em 03/08/2010, DJe 14/09/2010. 
Em tais casos, para além da duvidosa eficácia das terapias pretendidas, a princípio nenhuma preocupação subsiste com sua eventual extensão a todos os demais desafortunados cidadãos acometidos pelos mesmos infortúnios.

A reserva do impossível e o estado de coisas surreal por ela criado precisam ser seriamente debatidos pelos pensadores e operadores do sistema de justiça brasileiro, no intuito de se estabelecer objetivos, mecanismos, procedimentos e atores aptos à difícil e imprescindível tarefa de racionalizar e redimensionar a judicialização das políticas públicas - entre as quais a da saúde.

Não é apenas a judicialização da saúde que está em xeque, mas a saúde da própria judicialização: o Poder Judiciário, sob pena de perda de legitimidade, não pode mais esquivar-se de sua responsabilidade pelas escolhas sociais, políticas e econômicas que é obrigado a fazer no cumprimento de sua inafastável missão constitucional.

Não é difícil constatar, aliás, que a indiscriminada e desordenada concessão de tutelas individuais em temas afetos exclusivamente à política pública da saúde viola as garantias e princípios que o sistema constitucional lhe atribui.

Com efeito, os dois fundamentais dispositivos da Constituição Federal que enunciam a saúde como dever do Estado e direito de todos estabelecem claramente três paradigmas constitucionais que devem orientar a pertinente política pública: a universalidade, a isonomia e a preventividade, in litteris:

Art. 196. A saúde é direito de todos e dever do Estado, garantido mediante políticas sociais e econômicas que visem à redução do risco de doença e de outros agravos e ao acesso universal e igualitário às ações e serviços para sua promoção, proteção e recuperação.

Art. 198. As ações e serviços públicos de saúde integram uma rede regionalizada e hierarquizada e constituem um sistema único, organizado de acordo com as seguintes diretrizes:

I - descentralização, com direção única em cada esfera de governo;

II - atendimento integral, com prioridade para as atividades preventivas, sem prejuízo dos serviços assistenciais;

III - participação da comunidade (BRASIL, 1988).

Os mais recentes dados publicados pelo Conselho Nacional de Justiça (CNJ), referentes às ações judiciais na área da saúde no ano de 2019 revelam, todavia, que o sistema de justiça nacional segue em direção oposta.

Sistematicamente o Poder Judiciário defere tutelas individuais que, para além de inextensíveis a outros cidadãos que padecem das mesmas enfermidades (negando a universalidade e 
tratando os iguais desigualmente), revelam-se eminentemente curativas (e não preventivas) ${ }^{5}$. Assim, paradoxalmente, a tutela da saúde à brasileira nega e impede a implementação das diretrizes constitucionais a respeito da garantia das políticas públicas correlatas.

Não é preciso grande esforço para se concluir que é mais do que tempo de se reequacionar a tutela jurisdicional da saúde no Brasil, de modo a conciliar a imprescindível proteção da saúde e da vida de cada cidadão com a eficiente implementação de uma política pública que se revele efetivamente universal, igualitária e, preferencialmente, preventiva.

Por isso, no sentido da racionalização do sistema de justiça nacional para a resolução de controvérsias envolvendo políticas públicas, merece amplo debate e aprofundamento a adoção das técnicas de uniformização, coletivização e estruturação procedimental ${ }^{6}$.

Tais técnicas, aliadas à internalização de premissas econômicas básicas que devem orientar o processo político e jurídico de tomada de decisões a respeito da implementação das políticas públicas, apontam possíveis caminhos para a viabilização da proteção dos direitos fundamentais à vida e à saúde de forma adequada, isonômica e equitativa. A resposta a ser dada a essa questão, todavia, depende de quanto se deseja venham a ser universais, efetivas e isonômicas as políticas públicas de saúde no Brasil.

\section{A UNIFORMIZAÇÃO DE CRITÉRIOS PARA A TUTELA JURISDICIONAL DA SAÚDE POR VIA DOS PRECEDENTES DAS CORTES SUPERIORES}

Diante da explosão da judicialização da saúde, gradativamente o sistema de justiça brasileiro vem fixando parâmetros mínimos, verdadeiras guidelines que se prestam, acima de tudo, a orientar os magistrados no indeferimento de demandas evidentemente abusivas. Ao mesmo tempo, os referidos parâmetros intentam viabilizar tratamento minimamente isonômico.

O primeiro grande passo nesse sentido foi dado pelo Supremo Tribunal Federal no ano de 2009, quando foram remetidos à sua deliberação diversos pedidos de suspensão de decisões liminares deferidas para custeamento dos mais variados tratamentos e medicamentos não fornecidos pelo SUS.

Entre as ordens que se visava sustar estavam: o fornecimento de medicamentos, suplementos alimentares, órteses e próteses, criação de vagas em UTIs e leitos hospitalares, contratação de

5 De acordo com levantamento do Conselho Nacional de Justiça (CNJ DEBATE..., 2017), ao menos 1.346.931 processos com o tema saúde tramitaram no Judiciário naquele ano. A imensa maioria tratava de demandas individuais eminentemente curativas.

6 Sobre a necessidade de racionalização da judicialização da proteção dos direitos fundamentais, à luz do princípio da igualdade, ver SARMENTO (2008). 
servidores da saúde, realização de cirurgias e exames, e o custeio de tratamentos médicos fora do domicílio do paciente, inclusive no exterior ${ }^{7}$.

Por iniciativa do ministro Gilmar Mendes, foi realizada uma audiência pública na qual foram ouvidos cerca de 50 especialistas, entre os quais advogados, defensores públicos, membros do Ministério Público e do Poder Judiciário, professores, médicos, técnicos de saúde, gestores e usuários do Sistema Único de Saúde, no intuito de se obter informações técnicas, administrativas e econômicofinanceiras a respeito da gestão da saúde pública no País.

Com base nos dados colhidos, o STF teve a oportunidade de reafirmar, preliminarmente, a própria viabilidade constitucional de o Poder Judiciário imiscuir-se no controle de políticas públicas envolvendo o sistema de saúde pública. A seguir, o Tribunal acabou ponderando a respeito das consequências globais da destinação de recursos públicos para beneficiar apenas os indivíduos autores das ações judiciais.

Destacam-se, do voto do relator dos referidos pedidos de suspensão, ministro Gilmar Ferreira Mendes, as seguintes passagens:

\begin{abstract}
Se por um lado, a atuação do Poder Judiciário é fundamental para o exercício da efetiva cidadania, por outro, as decisões judiciais têm significado um forte ponto de tensão entre os elaboradores e os executores das políticas públicas, que se veem compelidos a garantir prestações de direitos sociais das mais diversas, muitas vezes contrastantes com a política estabelecida pelos governos para a área da saúde e além das possibilidades orçamentárias [...]. Nesse aspecto, não surpreende o fato de que a problemática dos direitos sociais tenha sido deslocada, em grande parte, para as teorias da justiça, as teorias da argumentação e as teorias econômicas do direito [...]. Assim, a garantia judicial da prestação individual de saúde, prima facie, estaria condicionada ao não comprometimento do funcionamento do Sistema Único de Saúde (SUS), o que, por certo, deve ser sempre demonstrado e fundamentado de forma clara e concreta, caso a caso (BRASIL, 2010, grifo do autor).
\end{abstract}

Concluindo o julgamento, o STF estabeleceu algumas diretrizes para o sistema de justiça a respeito da concessão de tutelas em ações referentes à saúde pública.

Especificamente no julgamento da Suspensão de Tutela Antecipada (STA) nº 175, o plenário da Suprema Corte definiu certos pressupostos ou parâmetros que devem ser observados pelos magistrados quando do julgamento das ações relativas às prestações relacionadas à saúde, estabelecidos em ordem de prioridade de cumprimento (BRASIL, 2010).

Em primeiro lugar, segundo o STF, faz-se necessário indagar se há uma política pública estatal que abranja a prestação de saúde pleiteada pela parte. Em tais casos, o Poder Judiciário deve intervir para seu cumprimento no caso de omissões ou prestação ineficiente. Na hipótese de inexistir

\footnotetext{
7 Agravos Regimentais nas Suspensões de Liminares nº 47 e 64, nas Suspensões de Tutela Antecipada nº 36, 185, 211 e 278, e nas Suspensões de Segurança nºs 2361, 2944, 3345 e 3355.
} 
política pública específica a satisfazer a pretensão do autor da demanda, deve o magistrado verificar se a prestação de saúde pleiteada está contida nos protocolos administrativos do SUS (BRASIL, 2010).

Caso não haja previsão do tratamento pelo SUS, segundo o Supremo Tribunal Federal, deve o magistrado ponderar três situações diversas:

i) quando a não prestação pelo SUS decorrer de uma omissão legislativa ou administrativa, a dispensação do tratamento seria em princípio dependente do registro do medicamento na Agência Nacional de Vigilância Sanitária (Anvisa) ou, quando menos, de prova efetiva de sua eficácia, impedindo-se sua importação (com exceção dos medicamentos adquiridos por intermédio de organismos multilaterais internacionais, desde que utilizados em programas de saúde pública do Ministério da Saúde);

ii) por outro lado, quando a não prestação pelo SUS derivar de decisão administrativa de não fornecimento, o juiz deve analisar se o SUS fornece tratamento alternativo, que será privilegiado em detrimento de outros, ressalvando-se contestação judicial a respeito no caso de ineficácia do tratamento. Na hipótese de a pretensão deduzida na ação dizer respeito a medicamentos e tratamentos experimentais, o Estado não estará obrigado a fornecê-los;

iii) por fim, caso se trate de pretensão de aquisição de tratamentos novos ainda não incluídos nos protocolos do SUS, mas já fornecidos pela rede particular de saúde, as tutelas judiciais podem ser deferidas, desde que seguidas de ampla instrução probatória e com reduzida possibilidade de deferimentos cautelares (BRASIL, 2010).

Após a fixação dos mencionados critérios por via do julgamento da STA n ${ }^{\circ}$ 175, o Supremo Tribunal Federal ainda fixou importantes precedentes obrigatórios, no julgamento de recursos extraordinários submetidos ao regime de repercussão geral - ambos relacionados à judicialização da saúde.

A respeito da obrigação de o Poder Público fornecer medicamentos de alto custo, o STF fixou precedente no sentido de que o Estado não é obrigado a fornecê-los por ordem judicial quando não estiverem previstos na relação do Programa de Dispensação de Medicamentos em Caráter Excepcional, do Sistema Único de Saúde ${ }^{8}$.

Referentemente ao fornecimento de medicamentos experimentais, fixou o STF precedente vinculante no sentido de que o Estado não está obrigado a fornecê-los, na medida em que a ausência de registro na Anvisa impede, como regra geral, o fornecimento de medicamento por decisão judicial.

8 Tema 6, fixado a partir do julgamento do RE $n^{\circ}$ 566.471/RN. As situações excepcionais ainda serão definidas pela Corte Suprema na formulação da tese de repercussão geral. 
Entretanto, decidiu a Corte Suprema ser possível, excepcionalmente e em demandas propostas exclusivamente contra a União Federal, a concessão judicial de medicamento sem registro sanitário, em caso de mora irrazoável da Anvisa em apreciar o pedido, desde que preenchidos três requisitos: “(i) a existência de pedido de registro do medicamento no Brasil (salvo no caso de medicamentos órfãos para doenças raras e ultrarraras); (ii) a existência de registro do medicamento em renomadas agências de regulação no exterior; e (iii) a inexistência de substituto terapêutico com registro no Brasil"9.

O Superior Tribunal de Justiça (STJ), por sua vez, já firmou importantes precedentes vinculantes ao julgar recursos especiais repetitivos em matéria de saúde.

A respeito da aplicação de medidas executivas indiretas para a consecução do fiel cumprimento de decisões mandamentais ordenando o fornecimento de medicamentos, decidiu a Corte que “cabe ao Juiz adotar medidas eficazes à efetivação de suas decisões, podendo, se necessário, determinar até mesmo o sequestro de valores do devedor (bloqueio), segundo o seu prudente arbítrio, e sempre com adequada fundamentação” (BRASIL, 2013) ${ }^{10}$.

Também definiu, o STJ, a possibilidade de imposição de multa diária (astreintes) a ente público, para compeli-lo a fornecer medicamento à pessoa desprovida de recursos financeiros $(\text { BRASIL, 2014a) })^{11}$.

A respeito da obrigatoriedade de o Poder Público fornecer medicamentos não incorporados em atos normativos do SUS, a Corte Superior definiu a necessidade da presença cumulativa dos seguintes requisitos: i) comprovação, por meio de laudo médico fundamentado e circunstanciado expedido por médico que assiste o paciente, da imprescindibilidade ou necessidade do medicamento, assim como da ineficácia, para o tratamento da moléstia, dos fármacos fornecidos pelo SUS; ii) incapacidade financeira, do paciente, de arcar com o custo do medicamento prescrito; iii) existência de registro do medicamento na Anvisa, observados os usos autorizados pela agência ${ }^{12}$.

Por fim, o STJ firmou precedente vinculante no sentido de que as operadoras de planos de saúde não estão obrigadas a fornecer medicamento não registrado pela Anvisa (BRASIL, 2019) ${ }^{13}$.

Como se percebe, as Cortes Superiores avançam na fixação de precedentes vinculantes no campo da judicialização da saúde, o que revela promissora notícia no caminho da racionalização e da isonomia da prestação jurisdicional.

\footnotetext{
9 Tese fixada no julgamento do RE $n^{\circ}$ 657.718/MG.

10 Tema $n^{\circ} 84$, firmado a partir do julgamento do REsp $n^{\circ} 1.069 .810 / \mathrm{RS}$.

11 Tema . $^{\circ}$ 98, firmado a partir dos REsp n ${ }^{\circ} 1.474 .665 / R S$ e do REsp n ${ }^{\circ} 1.101 .725 / R S$.

12 Tema $\mathrm{n}^{\circ}$ 106, firmado a partir dos julgamentos do REsp 1.657.156/RJ e do REsp $\mathrm{n}^{\circ} 1.102 .457 / \mathrm{RJ}$.

13 Tema $n^{\circ}$ 990, firmado a partir dos julgamentos do REsp n. ${ }^{\circ} 1.726 .563 /$ SPP e do REsp n. ${ }^{\circ} 1.712 .163 /$ SP.
} 
Todavia, a fixação de precedentes, por si só, não garante a distribuição efetiva, adequada e isonômica da proteção à vida e à saúde dos cidadãos brasileiros.

É preciso, nesse sentido, repensar a forma da prestação jurisdicional em matéria de saúde, o que suscita os temas da coletivização e da estruturação dos processos judiciais.

\section{A COLETIVIZAÇÃO DAS DEMANDAS PARA A IMPLEMENTAÇÃO DE POLÍTICAS PÚBLICAS DA SAÚDE}

Os direitos fundamentais à vida e à saúde podem ser inferidos a partir de dimensões difusa, coletiva e individual, segundo classificação estabelecida no sistema normativo brasileiro. O Código de Defesa do Consumidor (Lei $n^{0}$ 8.078/1990) implementou expressa e didática conceituação a respeito dos interesses ou direitos difusos, coletivos e individuais homogêneos (art. 81, parágrafo único). Enquanto os dois primeiros são compreendidos como transindividuais e indivisíveis, os direitos individuais homogêneos decorrem da origem comum que liga diversas pretensões ontologicamente individuais ${ }^{14}$.

A partir disso, o acesso à justiça para se requerer tutela jurisdicional da vida e da saúde no Brasil é viável tanto em âmbito individual (mediante demandas propostas diretamente pelos cidadãos interessados na própria proteção) como também por via representativa em âmbito coletivo. Por iniciativa de instituições legitimadas, as ações coletivas, caso julgadas procedentes, projetam eficácia erga omnes ou ultra partes. Segundo o sistema de tutela coletiva nacional, ainda, as ações coletivas não induzem litispendência para as demandas individuais correlatas, o que teoricamente autoriza a confluência de umas e outras.

Conforme dispõe o art. 104 da Lei nº 8.078/1990,

As ações coletivas, previstas nos incisos I e II e do parágrafo único do art. 81, não induzem litispendência para as ações individuais, mas os efeitos da coisa julgada erga omnes ou ultra partes a que aludem os incisos II e III do artigo anterior não beneficiarão os autores das ações individuais, se não for requerida sua suspensão no prazo de trinta dias, a contar da ciência nos autos do ajuizamento da ação coletiva (BRASIL, 1990).

Essa dualidade de acessibilidade ao Poder Judiciário permitida pelo sistema nacional revelase especialmente complexa quando se pretende a implementação ou a execução de políticas públicas, na medida em que pode projetar diferentes pretensões de tutela (difusa, coletiva e individual). A judicialização da saúde é um bom exemplo disso.

14 Sobre o tema, na doutrina italiana, ver CAPPELLETTI (1976); na doutrina nacional, consulte-se GRINOVER (1984), NERY JUNIOR (1983) e VENTURI (2007). 
A grande questão passa a ser como o Poder Judiciário pode equacionar e racionalizar a proteção da saúde em todas as dimensões referidas.

Trata-se de garantir o acesso individual de todos aqueles que necessitem prestação jurisdicional urgente para a proteção da própria vida e saúde, sem descurar do necessário controle judicial da adequação e constante atualização da política pública previamente projetada pelo Poder Público, no Brasil, por via do Sistema Único de Saúde.

Se, por um lado, há inegável direito de ação individual para tutela particular de cada cidadão ao seu próprio bem-estar, por outro, os limites e pressupostos para que tal acessibilidade seja garantida são extremamente discutíveis, na medida em que invariavelmente impactam estrutural e financeiramente a respectiva política pública.

O que se percebe com nitidez é uma verdadeira apropriação privada da política pública por parte dos autores de demandas individuais que, relembre-se, não mais se contentam em tão somente exigir do Estado a dispensação de medicamentos e terapias previamente definidas como de distribuição geral, gratuita e equitativa ${ }^{15}$.

Cada vez mais, na exata medida dos avanços científicos, tecnológicos e informacionais, os utentes do sistema de saúde apostam em pretensões de acesso a tratamentos e medicamentos muitas vezes nem sequer imaginados pelos gestores públicos. Não é preciso grande esforço para se compreender de que maneiras tais pretensões - levadas ao sistema de justiça por via de milhares de demandas individuais - impactam (quando não inviabilizam) o Sistema Único de Saúde.

Por tal motivo, bem avançadas as discussões a respeito dos fundamentos e limites políticoconstitucionais da intervenção jurisdicional nas políticas públicas no Estado Social, o grande desafio que também se coloca atualmente ao sistema de justiça brasileiro relaciona-se à forma de se permitir e de se garantir o controle jurisdicional da efetiva e adequada proteção da saúde.

Nesse passo, a coletivização da tutela jurisdicional referente à execução das políticas públicas preexistentes, assim como à implementação de outras tantas omitidas pelo Poder Público, parece ser o caminho a se seguir.

O acesso coletivo à justiça para a afirmação de políticas públicas em um país como o Brasil revela-se absolutamente imprescindível e estratégico. A afirmação faz sentido não apenas porque o acesso individual ao Poder Judiciário ainda é precário, ineficiente e ainda capturado por poucos

\footnotetext{
15 Na crítica destacada por Wang (2009, p. 54), “[...] o caráter coletivo dos direitos sociais requer que políticas sejam pensadas coletivamente, o que os juízes, em regra, não fazem, principalmente porque não possuem informações essenciais para pensar uma política pública (SILVA, 2007) e também pela própria estrutura de um processo judicial, que se concentra no caso concreto objeto da disputa (AMARAL, 2001, p. 38)”.
} 
atores. Funda-se na ideia premissa de que a funcionalidade do sistema de tutela coletiva é a única que se presta a garantir a proteção universal, isonômica e equitativa para todos os administrados.

Atuações tópicas do Poder Judiciário que favoreçam indivíduos ou grupos de indivíduos em determinados casos concretos podem inviabilizar planejamentos de políticas públicas de longo prazo, destinadas a proteger um número maior de pessoas. Como já advertiam Holmes e Sunstein (1999, p. 95), o juiz decide qual a melhor forma de se aplicar esses recursos escassos, mesmo sabendo pouco ou quase nada sobre a política pública em questão, as finanças públicas e a capacidade de gasto do poder público, ou a respeito de outros problemas sociais que suscitem uma atuação governamental.

Mas a coletivização da tutela referente à política pública da saúde não deve ser encarada tão somente como uma aspiração social ou política: ela é, antes de tudo, uma imposição técnica do sistema processual brasileiro.

Neste sentido, não é convincente a tese segundo a qual a pluridimensionalidade dos direitos fundamentais implicaria a inviabilidade de se restringir o ajuizamento de demandas coletivas por parte de qualquer cidadão que se considerasse desatendido por parte do Estado.

Como sustenta Sarlet (2015):

\begin{abstract}
Muito embora a complexidade do tema e a diversidade dos argumentos não tenha permitido um inventário completo e nem uma análise pormenorizada, é possível, à luz das premissas lançadas e sumariamente desenvolvidas, apostar no acerto da tese de que tanto os direitos sociais (como, de resto, os direitos fundamentais no seu conjunto) em geral, quanto o direito à saúde em particular, possuem uma dupla dimensão individual e coletiva, e, nesta medida, uma titularidade - no que diz com a condição de sujeito de direitos subjetivos - igualmente individual e transindividual, tal como acertadamente vem sendo reconhecido pelo próprio STF. Cuida-se, portanto, de direitos de todos e de cada um, de tal sorte que o desafio é saber harmonizar, sem que ocorra a supressão de uma das dimensões, ambas as perspectivas.
\end{abstract}

Na verdade, sob o ponto de vista da própria titularidade das pretensões de tutela da saúde, carecem os cidadãos de legitimidade ativa ad causam para, por via de demandas individuais por eles propostas, deduzir pedidos de tutelas referentes a interesses ou direitos difusos, coletivos ou individuais homogêneos.

O sistema processual coletivo nacional confere referida legitimação tão somente para instituições previamente definidas (o Ministério Público, a Defensoria Pública, as associações civis, os sindicatos e as pessoas jurídicas de direito público).

Toda e qualquer pretensão de intervenção jurisdicional direcionada a impor ao Poder Público implementação ou inovação de políticas públicas alicerça-se nas premissas de universalidade, de isonomia e de equidade. Assim sendo, a evidente dimensão geral e transindividual dessas pretensões as qualifica como relativas a interesses ou direitos transindividuais. Assim sendo, não cabe a dedução 
jurisdicional de tutelas coletivas e difusas por via de ações individuais, na exata medida em que inexiste direito subjetivo puramente individual à alteração ou à inauguração de uma nova política pública.

Por via de demandas individuais (sempre cabíveis, sob a premissa da inafastabilidade), somente é dado aos autores pleitear a execução de políticas públicas previamente estabelecidas e que estejam sendo olvidadas ou insatisfatoriamente prestadas, gerando lesão ou ameaça de lesão a direito individual patrimonial e/ou extrapatrimonial.

O sistema processual clássico, que rege a admissão, tramitação e julgamento das ações individuais, funda-se precisamente na lógica da referibilidade entre a legitimidade ativa ad causam (ligada à afirmação da titularidade da pretensão individual deduzida) e a formação da coisa julgada restritamente entre as partes. Por outro lado, o sistema processual coletivo foi projetado para viabilizar a representação em juízo dos interesses ou direitos transindividuais (tais como se revelam as pretensões de implementação de políticas públicas), objetivando a extensão da eficácia do julgado erga omnes.

Assim sendo, relativamente à judicialização da saúde, a lógica do sistema de tutela jurisdicional brasileira conduz à conclusão segundo a qual, sempre que a pretensão extrapolar o controle judicial da adequada execução da política pública da saúde para o fim de suscitar verdadeira intervenção do Poder Judiciário (por exemplo, para que novas terapias ou medicamentos passem a ser incorporados e dispensados universalmente pelo SUS), a forma de se invocar a tutela jurisdicional deve se dar única e exclusivamente por via das demandas coletivas.

Essa lógica processual, que coloca nos seus devidos lugares as demandas individuais e as demandas coletivas no campo da judicialização da saúde, já foi há muito prescrita por Barroso (2007) como um dos parâmetros indispensáveis para a racionalização do controle jurisdicional dessa política pública no País. São dele as seguintes conclusões:

A) As pessoas necessitadas podem postular judicialmente, em ações individuais, os medicamentos constantes das listas elaboradas pelo Poder Público e, nesse caso, o réu na demanda haverá de ser o ente federativo - União, Estado ou Município - que haja incluído em sua lista o medicamento solicitado. Trata-se aqui de efetivar uma decisão política específica do Estado, a rigor já tornada jurídica.

B) No âmbito de ações coletivas e/ou de ações abstratas de controle de constitucionalidade, será possível discutir a inclusão de novos medicamentos nas listas referidas. Tal inclusão, contudo, deve ser excepcional, uma vez que as complexas avaliações técnicas - de ordem médica, administrativa e orçamentária - competem primariamente aos Poderes Legislativo e Executivo.

C) Nas discussões travadas em ações coletivas ou abstratas - para a modificação das listas o Judiciário só deve determinar que a Administração forneça medicamentos de eficácia comprovada, excluindo-se os experimentais e os alternativos. Ademais, o Judiciário deve, como regra, optar por substâncias disponíveis no Brasil e por fornecedores situados no 
território nacional. Por fim, dentre os medicamentos de eficácia comprovada, deve privilegiar aqueles de menor custo, como os genéricos. (BARROSO, 2007, p. 36, grifo do autor).

Longe de ocasionar suposta violação de acesso à justiça, tal fórmula vem ao encontro não apenas da garantia do devido processo legal como, também, da igualdade, da universalidade e da equidade de tratamento efetivo de todos os cidadãos brasileiros.

Todavia, a realidade da praxe forense brasileira aponta para um absoluto descontrole no que diz respeito à admissibilidade de demandas individuais no campo da saúde.

Seja pela desconsideração de que não há legítima pretensão individual à alteração de políticas públicas, seja pela persistente ignorância das diferenças técnicas entre os sistemas de tutela jurisdicional individual e coletiva, não é possível simplesmente desconsiderar a realidade imposta pelo constante ajuizamento de milhares de demandas individuais no sistema de justiça brasileiro, pelas quais se deduzem pretensões de verdadeira alteração da política pública de saúde.

O que fazer com elas? Simplesmente inadmiti-las e instar as entidades colegitimadas a ajuizar as demandas coletivas correlatas? Ou admiti-las, a fim de lhes conferir um regime especial de tramitação que implique modalidade de conversão de demanda individual em demanda coletiva?

O novo Código de Processo Civil brasileiro pouco ou nada auxilia na busca por respostas para a racionalização do sistema de justiça. Por um lado, a mera comunicação judicial endereçada às instituições legitimadas ao ajuizamento de ações coletivas a respeito da possível ocorrência de demandas repetitivas, objetivando a provocação do ajuizamento de demandas coletivas, parece não garantir nem uma coisa, nem outra. Conforme dispõe o art. 139 do CPC,

O juiz dirigirá o processo conforme as disposições deste Código, incumbindo-lhe: [...] $\mathrm{X}$ - quando se deparar com diversas demandas individuais repetitivas, oficiar o Ministério Público, a Defensoria Pública e, na medida do possível, outros legitimados a que se referem o art. $5^{\circ}$ da Lei $\mathrm{n}^{\circ} 7.347$, de 24 de julho de 1985, e o art. 82 da Lei no 8.078, de 11 de setembro de 1990, para, se for o caso, promover a propositura da ação coletiva respectiva (BRASIL, 2015).

O referido dispositivo, em verdade, não representa nem inovação, nem realista perspectiva de aperfeiçoamento do sistema de tutela coletiva, na medida em que deriva de outro dispositivo normativo existente desde 1985 no País, mas comumente ignorado. Segundo o art. $7^{\circ}$ da Lei da Ação Civil Pública (Lei n 7.347/1985), “Se, no exercício de suas funções, os juízes e tribunais tiverem conhecimento de fatos que possam ensejar a propositura da ação civil, remeterão peças ao Ministério Público para as providências cabíveis” (BRASIL, 1985).

Por outro lado, a única previsão contida no texto do novo CPC aprovado pelo Parlamento que versava sobre tutela coletiva - relativa à conversão de ações individuais em ações coletivas - não 
foi sancionada, sendo vetada pela Presidência da República por força de forte oposição da Ordem dos Advogados do Brasil. Eis o texto vetado do art. 333 do CPC:

\begin{abstract}
Atendidos os pressupostos da relevância social e da dificuldade de formação do litisconsórcio, o juiz, a requerimento do Ministério Público ou da Defensoria Pública, ouvido o autor, poderá converter em coletiva a ação individual que veicule pedido que: I - tenha alcance coletivo, em razão da tutela de bem jurídico difuso ou coletivo, assim entendidos aqueles definidos pelo art. 81, parágrafo único, incisos I e II, da Lei n ${ }^{\circ} 8.078$, de 11 de setembro de 1990 (Código de Defesa do Consumidor), e cuja ofensa afete, a um só tempo, as esferas jurídicas do indivíduo e da coletividade; II - tenha por objetivo a solução de conflito de interesse relativo a uma mesma relação jurídica plurilateral, cuja solução, por sua natureza ou por disposição de lei, deva ser necessariamente uniforme, assegurando-se tratamento isonômico para todos os membros do grupo (BRASIL, 2015).
\end{abstract}

Apesar do veto à coletivização de demandas individuais, ainda assim parece viável, de lege lata, solução que pragmaticamente conduz a resultado similar. Vetos parlamentares, sempre é bom lembrar, não constituem legislação negativa. Não constituem por si próprios qualquer óbice para que resultados práticos equivalentes aos idealizados pelo texto vetado possam vir a ser construídos por via de interpretações sistemáticas e teleológicas ${ }^{16}$.

É, neste entender, precisamente o que ocorre com a possível coletivização das ações individuais de tutela da saúde.

Instaurada uma demanda individual pela qual se pretenda impor ao SUS custeamento de novos tratamentos ou medicamentos em prol do autor (ainda que se trate de hipótese de ilegitimidade ativa ad causam, como adiante se defende), nada impede que, após analisada possível medida de urgência necessária à proteção da saúde e da vida do demandante, o processo possa vir a ser efetivamente coletivizado. Para tanto, bastaria a convocação de entidades colegitimadas (entre as quais, a Defensoria Pública e o Ministério Público) para que, eventualmente, viessem a assumir o polo ativo da demanda, reconfigurando-a a uma dimensão transindividual, no intuito da obtenção de eficácia erga omnes do provimento de procedência.

Nesse exato sentido, Cambi e Fogaça (2017, p. 407) sustentam que

[...] apesar do veto ao incidente de coletivização, como é dever do juiz determinar o saneamento de vícios processuais (art. 139, inc. IX, CPC), o princípio da instrumentalidade recomenda que o magistrado, ao invés de indeferir a petição inicial por falta de condição da ação e resolver o processo sem julgamento de mérito (arts. 330, inc. I, e 485, inc. I, CPC), aplique, por analogia o disposto no artigo $9^{\circ}$ da Lei 4.717/65, com reforço do artigo 139, inc. $\mathrm{X}$, do CPC, e oficie a um dos colegitimados para, querendo, prosseguir no curso da ação, com a possibilidade de aditar ou emendar a petição inicial, a fim de transformar a ação, inicialmente individual, em coletiva.

16 Sobre o assunto, ver VENTURI (2000, p. 134). 
Entretanto, como adiante se esclarece, a coletivização deve ser acompanhada de uma necessária estruturação do procedimento, a viabilizar uma gestão processual que permita, por exemplo, a relativização de preclusões (sobretudo de alterações objetivas e subjetivas da demanda), decisões e execuções estruturais.

\section{DA ESTRUTURAÇÃO DOS PROCESSOS DE IMPLEMENTAÇÃO DE POLÍTICAS PÚBLICAS}

A pura e simples coletivização das pretensões de inovação das políticas públicas, tal como a da saúde, por si só, não é suficiente para garantir adequada e igualitária proteção jurisdicional aos utentes do Sistema Único de Saúde.

Isso se deve ao fato de que o sistema processual coletivo brasileiro, em que pese estar fundado em racionalidade e principiologia próprias e distintas daquelas inerentes ao sistema processual individual ${ }^{17}$, ainda é gravemente refém do procedimento comum ditado pela lógica das ações individuais.

Como não há previsão de relevantes especializações procedimentais da ação civil pública e das demais ações coletivas nacionais, acaba se aplicando às demandas coletivas o rito comum do Código de Processo Civil, conforme o art. 19 da Lei n 7.347/1985, “Aplica-se à ação civil pública, prevista nesta Lei, o Código de Processo Civil [...] naquilo em que não contrarie suas disposições” (BRASIL, 1985).

A adoção do rito comum previsto pelo Código de Processo Civil às ações coletivas, para além de ser de duvidosa constitucionalidade, gera notória deficiência, insuficiência e subversão do sistema de tutela jurisdicional dos interesses ou direitos transindividuais.

Apenas como ilustração, há muito se destaca a necessidade de adoção de um modelo diferenciado de devido processo social para a legítima adjudicação das demandas coletivas no País. Isso implicaria profundas alterações não apenas na forma de ser do processo coletivo, mas em sua compreensão como instrumento democrático de proteção dos direitos e garantias sociais fundamentais e da promoção das políticas públicas correlatas (VENTURI, 1996).

Entre as possíveis alterações procedimentais imprescindíveis para adequar os processos coletivos à sua natural complexidade, pode-se destacar a subdivisão das demandas coletivas de acordo com as espécies de tutelas deduzidas, a relativização do sistema de preclusões relacionadas às

\footnotetext{
17 A respeito dos princípios fundamentais da tutela coletiva, ver VENTURI (2007).
} 
eventuais necessidades de alterações subjetivas e objetivas e a estruturação das decisões e da execução da tutela coletiva ${ }^{18}$.

Acima de tudo, não se pode olvidar que os processos adjudicatórios envolvendo a implementação de políticas públicas parecem não admitir - ao menos sob o ponto de vista de legitimidade democrática - a simples substituição das escolhas constitucionalmente imputadas ao Poder Público pelas escolhas do adjudicador - o Poder Judiciário. Consoante Wang (2009, p. 53):

[...] em um Estado democrático é indispensável que decisões sobre alocação de recursos sejam reservadas aos poderes políticos, pois estes foram democraticamente eleitos pelo povo para tanto e estão sujeitos a avaliações, principalmente nas eleições periódicas, o que não ocorre com os membros do Poder Judiciário.

Estudos sobre estruturação dos processos de implementação de políticas públicas vêm se disseminando e densificando na doutrina nacional, fundamentalmente preocupada em criar condições para um diálogo processual institucional entre os Poderes Públicos para a adequada tutela dos direitos fundamentais ${ }^{19}$.

A respeito da especialização do procedimento judicial para a solução de conflitos envolvendo a implementação de políticas públicas, inclusive, há projeto de lei em tramitação perante a Câmara dos Deputados. Trata-se do PL nº 8058/2014, proposto pelo deputado federal Paulo Teixeira, a partir de projeto acadêmico coordenado pela saudosa professora Ada Pellegrini Grinover. Entre as características dos processos especiais para o controle e intervenção em políticas públicas, conforme dispõe o parágrafo único do art. $2^{\circ}$ de referido PL, destacam-se:

I - estruturais, a fim de facilitar o diálogo institucional entre os Poderes;

II - policêntricas, indicando a intervenção no contraditório do Poder Público e da sociedade; III - dialogais, pela abertura ao diálogo entre o juiz, as partes, os representantes dos demais Poderes e a sociedade;

IV - de cognição ampla e profunda, de modo a propiciar ao juiz o assessoramento necessário ao pleno conhecimento da realidade fática e jurídica;

V - colaborativas e participativas, envolvendo a responsabilidade do Poder Público;

VI - flexíveis quanto ao procedimento, a ser consensualmente adaptado ao caso concreto;

VII - sujeitas à informação, ao debate e ao controle social, por qualquer meio adequado, processual ou extraprocessual;

VIII - tendentes às soluções consensuais, construídas e executadas de comum acordo com o Poder Público;

IX - que adotem, quando necessário, comandos judiciais abertos, flexíveis e progressivos, de modo a consentir soluções justas, equilibradas e exequíveis;

$\mathrm{X}$ - que flexibilizem o cumprimento das decisões;

XI- que prevejam o adequado acompanhamento do cumprimento das decisões por pessoas físicas ou jurídicas, órgãos ou instituições que atuem sob a supervisão do juiz e em estreito contato com este. (BRASIL, 2014b).

18 Muitas dessas alterações já foram idealizadas e sugeridas pelo Projeto de Lei nº 5.139/2009 (nova Lei da Ação Civil Pública).

19 Entre todos, vide ARENHART; JOBIM (2017); COSTA; WATANABE; GRINOVER (2017). 
Para tanto, parece claro que o modo de ser do processo civil deve ser repensado quanto aos critérios de admissibilidade, procedimentalização, julgamento e execução. O necessário envolvimento do Poder Público nessas demandas - não apenas como parte demandada, mas como ente representativo democraticamente eleito e constitucionalmente encarregado das escolhas políticas - deve ocasionar profundas alterações dos e nos processos adjudicatórios, conforme explica Arenhart (2013, p. 401):

\begin{abstract}
Enfim, deve haver ampla margem para a gestão da decisão judicial, de modo a compatibilizála com as necessidades da situação concreta e com as possibilidades das partes. Pode-se, por exemplo, ditar à Administração Pública o objetivo a ser alcançado, reservando-lhe a escolha dos meios e preservando sua discricionariedade, ou se pode estabelecer desde logo um cronograma de atividades a serem adotadas. Pode-se impor certas condutas ao réu, ou deixar essa determinação a um órgão técnico especializado. Pode-se escalonar medidas a serem adotadas no tempo, com prestação de contas periódicas, ou mesmo nomear um interventor fiscalizador para acompanhar o desenvolvimento da satisfação à prestação jurisdicional. Sem dúvida, essa flexibilização é essencial para a adequada proteção de certos interesses. Com efeito, a especialização de certos órgãos da Administração Pública podem [sic] torná-los, em relação ao órgão jurisdicional, um ambiente muito mais apropriado para a especificação das prestações específicas a serem realizadas ou mesmo para a avaliação da suficiência das medidas adotadas para a proteção do direito tutelado.
\end{abstract}

Entretanto, para além (e antes) de se repensar o processo de adjudicação do controle e implementação de políticas públicas, é necessário apostar fortemente no modelo de justiça consensual recentemente institucionalizado no Brasil, ancorado nos chamados meios adequados de resolução de conflitos (mediação, conciliação, negociação e arbitragem, entre outros) ${ }^{20}$.

Se o tradicional método de adjudicação se revela de duvidosa legitimidade e adequação quando utilizado para solucionar conflitos envolvendo o controle e implementação de políticas públicas, os instrumentos resolutórios consensuais surgem não como “alternativas”, mas, antes, como instrumentos mais adequados para tal objetivo.

Nesse sentido, a mediação, a conciliação e a negociação - porque construídos a partir de uma racionalidade baseada menos na contraposição entre os litigantes do que na coordenação dos envolvidos para a obtenção da melhor solução do conflito - surgem como mecanismos teoricamente idôneos a viabilizar a coordenação dos esforços das entidades administrativas que devem atuar para a promoção dos direitos fundamentais em grau universal e equitativo ${ }^{21}$.

\footnotetext{
20 A institucionalização dos mecanismos de resolução consensual dos conflitos no Brasil pode bem ser inferida a partir da edição da Lei de Mediação (Lei $n^{\circ}$ 13.140/2015), assim como do novo Código de Processo Civil (Lei $n^{\circ}$ 13.105/2015), que determinou a obrigatoriedade da tentativa de solução consensual pré-processual e endoprocessual. 21 Cf. WEBB (1992, p. 265).
} 
Seja como for, tanto os procedimentos judiciais como os administrativos, quando voltados para a resolução adjudicada ou consensual de conflitos relativos à implementação de políticas públicas, não podem mais prescindir de estruturações que se revelem adequadas ao caso concreto.

Nesse cenário, v.g., o próprio papel a ser desempenhado pela Administração Pública (geralmente, o de parte demandada) deve passar a ser reavaliado, na medida em que, muito mais do que se lhe impor ordens judiciais muitas vezes inexequíveis, a efetiva (re)adequação da política pública dependerá decisivamente de sua atuação, dentro de um processo estruturado e colaborativo.

\title{
5 A INSTRUMENTALIDADE DA ANÁLISE ECONÔMICA DO DIREITO PARA A ADEQUADA RESOLUÇÃO DOS CONFLITOS ENVOLVENDO POLÍTICAS PÚBLICAS
}

A uniformização, a coletivização e a estruturação dos processos adjudicatórios dos conflitos envolvendo o controle e a implementação de políticas públicas são caminhos imprescindíveis para a racionalização e a equidade da proteção dos direitos fundamentais.

Tais técnicas devem ser empregadas à luz da análise econômica do direito, precisamente na medida em que se revela instrumento que orienta as escolhas (administrativas e judiciais) não apenas mais racionais, mas sobretudo eficientes e igualitárias ${ }^{22}$.

É preciso, contudo, compreender o sentido e os limites da aplicação da análise econômica do direito em um sistema de justiça tradicionalmente refratário a qualquer influência econômica quando da proteção de direitos fundamentais:

\begin{abstract}
Em primeiro lugar, devem-se considerar as próprias limitações inerentes à ciência econômica, que se pretende meramente descritiva dos padrões de comportamento social. Por isso mesmo, as maiores críticas voltadas contra a análise econômica dizem respeito à assunção de premissas que se revelam muitas vezes irreais ou inatingíveis (unrealistic assumptions), ao emprego de um modelo estático de verificação do equilíbrio das relações sociais e ao reducionismo ao qual aparentemente conduz, na medida em que relega a realidade a um pequeno número de parâmetros puramente econômicos. Tais críticas (cuja pertinência usualmente é refutada pela doutrina da law and economics), todavia, não são capazes de obscurecer a relevância da análise econômica para a complementação e o enriquecimento do estudo do direito. Por outro lado, ao Direito não satisfaz uma leitura puramente econômica das relações jurídicas no intuito de orientar o legislador ou o julgador a respeito dos melhores caminhos em busca da maior eficiência. Isso porque, independentemente dela (e mesmo em desfavor dela), o próprio ordenamento constitucional dos "Estados Sociais" (como o brasileiro) já erige um complexo e amplíssimo sistema de garantias de direitos fundamentais (individuais e metaindividuais), cuja proteção prometida, muitas vezes, revela-se incompatível com os mais óbvios critérios de eficiência econômica. Esse antagonismo acima destacado, aliado a um possível superdimensionamento que vitimou a análise econômica do direito nas últimas décadas, acabou por criar um notável preconceito
\end{abstract}

22 Sobre os fundamentos da Law \& Economics, destacam-se ARAÚJO (2008a); COOTER (2005); GAROUPA (2012); LORENZETTI (2009); MATHIS (2009); POLINSKY (2003); POSNER (1983); SHAVELL (2004). Especificamente sobre a análise econômica do processo civil, consultem-se as recentes obras FUX; BODART (2019); WOLKART (2019). 
contra o seu emprego, sobretudo em relação àqueles que nela veem uma indevida mecanização da distribuição da justiça ou o triunfo do mercado sobre os direitos fundamentais. [...] A aproximação entre Direito e Economia, portanto, deve estar devidamente informada pela diversidade fundamental das próprias racionalidades envolvidas que, se, por um lado, oportuniza o surgimento de importantes e cada vez mais ampliados modelos interpretativos dos fenômenos juridicamente relevantes, recomenda, por outro, que os juristas encarem a análise econômica muito mais como um instrumento que propicia a adequação do Direito ao tempo e ao espaço social do que um modelo finalístico com pretensões de ditar, autonomamente, o comportamento dos sistemas de justiça (VENTURI, 2014, p. 144-148, grifo do autor).

Um bom exemplo de adoção da racionalidade econômica para a construção de políticas públicas na área da saúde - ou para a possível resolução de conflitos dela derivados - pode ser inferido do modelo do Reino Unido.

A solução lá implementada para a gestão de demandas individuais na área da saúde foi a criação do chamado índice QALY (Quality Adjusted Life Years), utilizado pela agência reguladora National Institute for Health and Care Excellence (NICE).

Segundo Ferreira (2002, p. 10, grifo do autor),

Os QALYs (Quality-Adjusted Life Years) são utilizados quando estão em causa estas decisões sobre alocação de recursos no sector da saúde (tanto em termos particulares, como em decisões da sociedade em geral) como auxílio à tomada de decisão. Foram desenvolvidos na década de 70, como uma forma de integrar os ganhos em saúde de alterações, tanto em qualidade de vida, como em quantidade de vida, e integrar também ganhos entre indivíduos. Aquando do seu desenvolvimento, pretendia-se que os QALYs incorporassem tanto a morbilidade (ganhos em qualidade) como a mortalidade (ganhos em quantidade), combinando-as numa única medida.

Por via desse índice, calcula-se a razoabilidade e a viabilidade do fornecimento de um tratamento específico mediante cálculo que envolve a expectativa de vida do paciente com a terapia, multiplicada pela qualidade de vida, dividida pelo custo. Se o índice for baixo, o NICE não incorpora o tratamento em seu atendimento. Para além da adoção de referido índice, estabeleceu-se ainda um teto de 30 mil libras anuais, valor máximo que o governo inglês pode gastar com tratamentos individuais. Custos que excedam o referido teto devem ser arcados pelo cidadão, conforme informam Crepaldi e Moraes (2018).

A judicialização da saúde no Brasil, tal como tem ocorrido nos últimos anos, talvez constitua um dos melhores exemplos do paradoxo apontado pela análise econômica do direito como tragédia dos baldios e tragédia dos anti-baldios: quando poucos se apropriam, muito ganham; quando todos se apropriam, já não há mais muito o que ganhar ${ }^{23}$.

23 Cf. ARAÚJO (2008b). 
Por um lado, a complacência com a qual o Poder Judiciário brasileiro avaliza demandas individuais - com fundamento em conflitos envolvendo a políticas pública da saúde - abre espaço para a destinação judicial de bilhões de reais, ano após ano, para atender a condenações impostas ao Sistema Único de Saúde, em benefício de poucos.

Por outro lado, a coletivização da tutela jurisdicional de tais conflitos, na medida em que demanda tratamento racional e igualitário para todos os cidadãos, no mais das vezes já não consegue o mesmo grau de efetividade na tutela deduzida, pela projeção exponencial dos gastos públicos então necessários.

Qual seria o nível ótimo de acessibilidade, sob o ponto de vista da análise econômica do direito? Estaria, aliás, o sistema de justiça brasileiro preparado para incorporar as premissas da law \& economics para a gestão do Sistema Único de Saúde ou para a adjudicação dos milhares de conflitos dele exsurgidos? ${ }^{24}$

As respostas dependem do quão a sério se deseja levar os princípios constitucionais de universalidade, isonomia e preventividade na proteção da saúde dos brasileiros.

De todos os brasileiros.

\section{REFERÊNCIAS}

ARAÚJO, Fernando. A tragédia dos baldios e dos anti-baldios. O problema económico do nível óptimo de apropriação. Coimbra: Almedina, 2008b.

ARAÚJO, Fernando. Análise económica do direito. Programa e guia de estudo. Coimbra: Almedina, 2008a.

ARENHART, Sérgio Cruz. Decisões estruturais no direito processual civil brasileiro. Revista de Processo, a. 38, v. 225, p. 389-410. São Paulo: Editora Revista dos Tribunais, 2013.

ARENHART, Sérgio; JOBIM, Marco Félix. Processos Estruturais. Salvador: Juspodium, 2017.

BARROSO, Luís Roberto. Da falta de efetividade à judicialização excessiva: direito à saúde, fornecimento gratuito de medicamentos e parâmetros para a atuação judicial. Interesse Público, Belo Horizonte, v. 9, n. 46, nov. 2007. Disponível em: https://bit.ly/3r6ZGQy. Acesso em: 24 ago. 2019.

24 Segundo WOLKART (2019, p. 133, grifo do autor), "No Brasil, boa parte das normas e da doutrina de direito processual não utiliza técnicas de entendimento do comportamento humano, nem está voltada para um objetivo palpável (aumento do bem-estar social), resultando em mecanismos que acabam agravando o cenário de tragédia da justiça. Assim, pensamos que a adoção de modelos econômicos simples, utilizados pela psicologia e pela neurociência, podem proporcionar um grande avanço”. 
BRASIL. CÂMARA DOS DEPUTADOS. (Deputado Federal Paulo Teixeira). Projeto de Lei n. ${ }^{\mathbf{0}}$ 8058/2014. Institui processo especial para o controle e intervenção em políticas públicas pelo Poder Judiciário e dá outras providências. 2014b. Disponível em: https://bit.ly/2IU4q7U. Acesso em: 21 fev. 2020.

BRASIL. Constituição da República Federativa do Brasil de 1988. Brasília, DF: Presidência da República, [2018]. Disponível em: https://bit.ly/2sVjudp. Acesso em: 1 jul. 2019.

BRASIL. Lei n. ${ }^{0}$ 13.105, de 16 de março de 2015. Código de Processo Civil. Disponível em: https://bit.ly/1VojI3i. Acesso em: 23 ago. 2019.

BRASIL. Lei n. ${ }^{0}$ 7.347, de 24 de julho de 1985. Disciplina a ação civil pública de responsabilidade por danos causados ao meio-ambiente, ao consumidor, a bens e direitos de valor artístico, estético, histórico, turístico e paisagístico (VETADO) e dá outras providências. Disponível em: https://bit.ly/1siiVpS. Acesso em: 23 ago. 2019.

BRASIL. Lei no 8.078, de 11 de setembro de 1990. Dispõe sobre a proteção do consumidor e dá outras providências. Disponível em: https://bit.ly/18lUsHh. Acesso em: 13 ago. 2019.

BRASIL. Superior Tribunal de Justiça. Recurso Especial n. ${ }^{\mathbf{0}}$ 1.069.810/RS. Relator: Ministro Napoleão Nunes Maia Filho. Julgado em 23 out. 2013. Publicano no DJe de 06 nov. 2013. Disponível em: shorturl.at/eAMWX. Acesso em: 31 mar. 2020.

BRASIL. Superior Tribunal de Justiça. Tema Repetitivo n. ${ }^{0}$ 98. Órgão Julgador: Primeira Seção. Data de Desafetação: 09 jun. 2014a. Disponível em: shorturl.at/rzNQ7. Acesso em: 31 mar. 2020.

BRASIL. Superior Tribunal de Justiça. Tema Repetitivo n. ${ }^{\circ}$ 990. Órgão Julgador: Segunda Seção. Data de Desafetação: 27 nov. 2019. Disponível em: shorturl.at/DEHP6. Acesso em: 31 mar. 2020.

BRASIL. Supremo Tribunal Federal. Agravo Regimental na Suspensão de Tutela Antecipada (STA) n. ${ }^{0}$ 175. Relator: Min. Gilmar Mendes (Presidente), Tribunal Pleno, julgado em 17 mar. 2010. DJe-076 publicado em 30 abr. 2010. Disponível em: https://bit.ly/2Ff7uuj. Acesso em: 18 jul. 2019.

BRASIL. Supremo Tribunal Federal. Arguição de Descumprimento de Preceito Fundamental n. ${ }^{\circ}$ 45/DF. ADPF - Políticas Públicas - Intervenção Judicial - "Reserva do Possível". Relator: Min. Celso de Mello, j. 29/04/2004, DJ 04/05/2004. Disponível em: https://bit.ly/2IHBRtj. Acesso em: 9 ago. 2019.

BRASIL. Supremo Tribunal Federal. Recurso Extraordinário n. ${ }^{\circ}$ 566.471/RN. Relator: Min. Marco Aurélio Mello, julgado em 15 nov. 2007, DJe-157, div. 06 dez. 2007, pub. 07 dez. 2007, p. 016. Disponível em: https://bit.ly/2ddqeM5. Acesso em: 14 ago. 2019.

BRASIL. Supremo Tribunal Federal. Recurso Extraordinário n. ${ }^{0}$ 657.718/MG. Relator: Min. Marco Aurélio, Data de Julgamento: 17 nov. 2011, Data de Publicação: DJe-051 12 mar. 2012. Disponível em: https://bit.ly/2AaIWRp. Acesso em: 14 ago. 2019.

BUCCI, Maria Paula Dallari. Contribuição para a redução da judicialização da saúde. Uma estratégia jurídico-institucional baseada na abordagem de Direito e Políticas Públicas. In: BUCCI, 
Maria Paula Dallari; DUARTE, Clarice Seixas (Org.). Judicialização da Saúde: a visão do poder executivo. São Paulo: Saraiva, 2017.

CAMBI, Eduardo; FOGAÇA, Marcos Vargas. Conversão da ação individual em ação coletiva: análise do conteúdo do artigo 333 do CPC/2015, das razões do veto da Presidente da República e do aproveitamento do instituto no atual sistema processual. Revista Brasileira de Direito, Passo Fundo, v. 13, n. 2, p. 389-409, maio-ago. 2017.

CAPPELLETTI, Mauro. Appunti sulla tutela giurisdizionale di interessi collettivi o diffusi. In: Le azioni a tutela di interessi collettivi. Pádua: CEDAM, 1976.

CNJ DEBATE judicialização da saúde em audiência pública. Conselho Nacional de Justiça. Agência CNJ de notícias. Publicado em 11 dez. 2017. Disponível em: https://bit.ly/2CXGXD5. Acesso em: 19 maio 2019.

COOTER, Robert D. The Confluence of Justice and Efficiency in Economic Analysis of Law. In: PARISI, Francesco; ROWLEY, Charles (Coord.). The origins of law and economics, essays by the founding fathers. Edward Elgar Publishing, 2005.

COSTA, Susana Henriques da; WATANABE, Kazuo; GRINOVER, Ada Pellegrini. O processo para solução de conflitos de interesse público. Salvador: Juspodium, 2017.

CREPALDI, Thiago; MORAES, Claudia. Judicialização da saúde beneficia mercado e prejudica sociedade, diz pesquisador. Revista consultor jurídico, [s. l.], 12 mar. 2018. Disponível em: https://bit.ly/2IqfgDO. Acesso em: 12 set. 2019.

FERREIRA, Lara de Noronha. Utilidades, QALYS e medição da qualidade de vida. In: Associação portuguesa da economia da saúde (documento de trabalho $\mathrm{n}^{\circ}$ 01/2002). Disponível em: https://bit.ly/2KoRgDm. Acesso em: 18 ago. 2019.

FUX, Luiz; BODART, Bruno. Processo Civil e Análise Econômica. Rio de Janeiro: Editora Forense, 2019.

GAROUPA, Nuno. Combinar a economia e o Direito. A análise econômica do Direito. 2012. Disponível em: https://bit.ly/3lvol05. Acesso em: 5 fev. 2020.

GRINOVER, Ada P. A problemática dos interesses difusos. In: A tutela dos interesses difusos. São Paulo: Max Limonad, 1984.

HOLMES, Stephen; SUNSTEIN, Cass R. The cost of rights: why liberty depends on taxes. New York, W. W. Norton \& Company, 1999.

INSTITUTO DATAFOLHA. Avaliação do presidente Michel Temer. Pesquisa de Opinião (PO) $n^{0}$ 813.956, registrada no Tribunal Superior Eleitoral com o n ${ }^{0}$ BR 08510/2018. Abr. 2018. Disponível em: https://bit.ly/2ISRhMv. Acesso em: 14 ago. 2019.

JUDICIALIZAÇÃO da saúde: iniciativas do CNJ são destacadas em seminário no STJ. Conselho Nacional de Justiça. Agência CNJ de notícias. Publicado em 22 maio 2018. Disponível em: https://bit.ly/2Y5PbiA. Acesso em: 8 dez. 2019. 
LORENZETTI, Ricardo Luis. Teoria da decisão judicial: fundamentos de direito. Tradução Bruno Miragem. São Paulo: Revista dos Tribunais, 2009.

MATHIS, Klaus. Efficiency instead of justice? Searching for the Philosophical Foundations of the Economic Analysis of Law. Tradução Deborah Shannon. Law and philosophy library, v. 84. New York: Springer, 2009.

MUNIZ, Mariana. Judicialização da saúde resultou em 1,5 milhão de processos em 2017. Jota (online). Publicado em 12/12/2017. Disponível em: https://bit.ly/2XYczi7. Acesso em: 6 out. 2019.

NERY JUNIOR, Nelson. A ação civil pública. RePro, n. 31, p. 224-232. São Paulo: RT, jul.set./1983.

POLINSKY, Mitchell A. An introduction to law and economics. 3. ed. New York: Aspen Publishers, 2003.

POSNER, Richard. The economics of Justice. Cambridge: Harvard University Press, 1983.

SARLET, Ingo Wolfgang. A titularidade simultaneamente individual e transindividual dos direitos sociais analisada à luz do exemplo do direito à proteção e promoção da saúde. Páginas de Direito, [s. l.], 12 maio 2015. Disponível em: https://bit.ly/3cSOuBW. Acesso em: 6 out. 2019.

SARMENTO, Daniel. A Proteção Judicial dos Direitos Sociais: Alguns Parâmetros Ético-Jurídicos. In: SARMENTO, Daniel; SOUZA NETO, Cláudio Pereira de (Coord.). Direitos Sociais:

Fundamentos, Judicialização e Direitos Sociais em Espécie. Rio de Janeiro: Lumen Juris, 2008. p. 533-586.

SHAVELL, Steven. Foundations of economics analysis of law. Cambridge: Harvard University Press, 2004.

VENTURI, Elton. Apontamentos sobre o processo coletivo, o acesso à justiça e o devido processo social. Revista Gênesis de direito processual civil, Curitiba, v. 39, 1996.

VENTURI, Elton. Execução da tutela coletiva. São Paulo: Malheiros, 2000.

VENTURI, Elton. Processo civil coletivo. São Paulo: Malheiros, 2007.

VENTURI, Thaís G. P. Responsabilidade civil preventiva: a proteção contra a violação dos direitos e a tutela inibitória material. São Paulo: Malheiros, 2014.

WANG, Daniel Wei Liang. Poder Judiciário e políticas públicas de saúde: participação democrática e equidade. Cadernos gestão pública e cidadania, [s. l.], v. 14, n. 54, p. 51-87, jan. 2009.

Disponível em: https://bit.ly/2XVFQdm. Acesso em: 18 ago. 2019.

WEBB, Janette. Arbitration: Semi-judicial process or negotiation? Current psychological reviews, [s. l.], v. 2, 1992.

WOLKART, Erik Navarro. Análise econômica do processo civil: como a economia, o direito e a psicologia podem vencer a tragédia da justiça. São Paulo: Thomson Reuters Brasil, 2019. 